\title{
The $\alpha_{1 E}$ Calcium Channel Exhibits Permeation Properties Similar to Low-Voltage-Activated Calcium Channels
}

\author{
Emmanuel Bourinet, ${ }^{1}$ Gerald W. Zamponi, ${ }^{1}$ Anthony Stea, ${ }^{1}$ Tuck W. Soong, ${ }^{1}$ Bertram A. Lewis, ${ }^{2}$ \\ Lisa P. Jones, ${ }^{2}$ David T. Yue, ${ }^{2}$ and Terry P. Snutch ${ }^{1}$ \\ ${ }^{1}$ Biotechnology Laboratory, University of British Columbia, Vancouver, British Columbia, Canada V6T 1Z3, and \\ 2Department of Biomedical Engineering, Johns Hopkins University School of Medicine, Baltimore, Maryland 21205
}

The physiological and pharmacological properties of the $\alpha_{1 \mathrm{E}}$ calcium (Ca) channel subtype do not exactly match any of the established categories described for native neuronal $\mathrm{Ca}$ currents. Many of the key diagnostic features used to assign cloned $\mathrm{Ca}$ channels to their native counterparts, however, are dependent on a number of factors, including cellular environment, $\beta$ subunit coexpression, and modulation by second messengers and G-proteins. Here, by examining the intrinsic pore characteristics of a family of transiently expressed neuronal $\mathrm{Ca}$ channels, we demonstrate that the permeation properties of $\alpha_{1 \mathrm{E}}$ closely resemble those described for a subset of lowthreshold Ca channels. The $\alpha_{1 \mathrm{~A}}$ (P-/Q-type), $\alpha_{1 \mathrm{~B}}$ (N-type), and $\alpha_{1 \mathrm{C}}$ (L-type) high-threshold $\mathrm{Ca}$ channels all exhibit larger whole-cell currents with barium $(\mathrm{Ba})$ as the charge carrier as compared with $\mathrm{Ca}$ or strontium (Sr). In contrast, macroscopic $\alpha_{1 \mathrm{E}}$ currents are largest in $\mathrm{Sr}$, followed by $\mathrm{Ca}$ and then $\mathrm{Ba}$. The unique permeation properties of $\alpha_{1 \mathrm{E}}$ are maintained at the single-channel level, are independent of the nature of the expression system, and are not affected by coexpression of $\alpha_{2}$ and $\beta$ subunits. Overall, the permeation characteristics of $\alpha_{1 \mathrm{E}}$ are distinct from those described for R-type currents and share some similarities with native low-threshold Ca channels.

Key words: calcium channel; permeation; barium; strontium; transient expression; conductance; pore properties
Calcium (Ca) influx through voltage-dependent $\mathrm{Ca}$ channels mediates a wide range of neurophysiological functions, including gene expression, neurotransmitter release, and firing patterns (Tsien et al., 1988). On the basis of their electrophysiological and pharmacological properties, Ca channels have been classified into T-, L-, N-, P-, and Q-types (for review, see Stea et al., 1995b). T-type channels transiently activate at relatively negative membrane potentials, whereas the other channel types first activate at more positive potentials and display diverse kinetic characteristics. The high threshold channels can also be distinguished pharmacologically: L-type channels are sensitive to dihydropyridine agonists and antagonists, N-type channels are blocked by $\omega$-conotoxin GVIA, and P-type channels are sensitive to nanomolar concentrations of $\omega$-agatoxin IVA. Q-type channels are sensitive to both $\omega$-conotoxin MVII-C and $\omega$-agatoxin IVA and may be related structurally to P-type channels (Stea et al., 1994; Dunlap et al., 1995). To date, there are no known specific blockers of native low voltage-activated channels.

\footnotetext{
Received Feb. 29, 1996; revised May 23, 1996; accepted May 28, 1996.

This work was supported by postdoctoral fellowships from European Molecular Biology and Institut National de la Santé et de la Recherche Médicale to E.B. and by postdoctoral fellowships from the Medical Research Council (MRC) of Canada to G.W.Z. and A.S.; G.W.Z. also holds a postdoctoral fellowship from the Alberta Heritage Foundation for Medical Research. T.W.S. is supported by a postdoctoral fellowship and is on leave from the National Institute of Molecular and Cell Biology, National University of Singapore. B.A.L. and L.P.J. are supported by the National Institutes of Health Medical Scientist Training Program. D.T.Y. is supported by a Presidential Faculty Fellowship of the National Science Foundation. T.P.S. is an MRC Scientist and is supported by grants from the MRC and the Howard Hughes Medical Institute International Research Scholars Program. Travel support was provided by NATO Grant CRG 890374 to Joël Nargeot. We thank Drs. John Hanrahan and Mary Gilbert for comments on this manuscript and Dr. Andy Randall for providing unpublished information concerning R-type currents.

Correspondence should be addressed to Dr. Terry P. Snutch, Biotechnology Laboratory, Room 237, 6174 University Boulevard, University of British Columbia, Vancouver, British Columbia, Canada V6T 1 Z3.

Copyright (C) 1996 Society for Neuroscience $0270-6474 / 96 / 164983-11 \$ 05.00 / 0$
}

In addition to their differential kinetic and pharmacological profiles, the major types of $\mathrm{Ca}$ channels display distinct permeation characteristics (Bean, 1985; Nilius et al., 1986; Carbone and Lux, 1987; Fox et al., 1987; Akaike et al., 1989; Takahashi et al., 1991). Of particular note, the relative permeabilities for $\mathrm{Ca}$, barium $(\mathrm{Ba})$, and strontium $(\mathrm{Sr})$ are dependent on the Ca channel subtype. In general, Ba permeates high voltage-activated Ca channels more effectively than $\mathrm{Ca}$ does, whereas low voltage-activated (T-type) $\mathrm{Ca}$ channels are permeated by $\mathrm{Ca}$ as well as or better than by Ba (Hille, 1992). Most neurons express multiple subtypes of Ca channels, however, making it difficult to determine the exact permeation properties of individual subtypes of neuronal $\mathrm{Ca}$ channels. Furthermore, to date, there has been no side-by-side comparison of the permeation characteristics of the major $\mathrm{Ca}$ channel subtypes under identical experimental conditions.

The expression of cloned $\mathrm{Ca}$ channels in exogenous systems has allowed the study of individual Ca channel subtypes in isolation. Five distinct $\mathrm{Ca}$ channel $\alpha_{1}$ subunit genes are expressed in the mammalian CNS $\left(\alpha_{1 \mathrm{~A}}, \alpha_{1 \mathrm{~B}}, \alpha_{1 \mathrm{C}}, \alpha_{1 \mathrm{D}}\right.$, and $\left.\alpha_{1 \mathrm{E}}\right)$. Functional expression and immunoprecipitation studies have demonstrated that $\alpha_{1 \mathrm{C}}$ and $\alpha_{1 \mathrm{D}}$ encode dihydropyridine-sensitive L-type channels (Williams et al., 1992a; Hell et al., 1993; Tomlinson et al., 1993), whereas $\alpha_{1 \text { B }}$ encodes an $\omega$-conotoxin-sensitive N-type channel (Dubel et al., 1992; Williams et al., 1992b; Fujita et al., 1993; Stea et al., 1993). The $\alpha_{1 \mathrm{~A}}$ channel displays properties similar to P- and Q-type currents (Mori et al., 1991, Sather et al., 1993; Stea et al., 1994), whereas $\alpha_{1 \mathrm{E}}$ does not fit exactly into any of the Ca channel subtypes described in native cells. Although $\alpha_{1 \mathrm{E}}$ channels differ from T-type channels expressed in endocrine and cardiac cells, they display several properties consistent with a subset of mid- to low-threshold $\mathrm{Ca}$ channels expressed in the brain, including relatively more negative potentials for halfactivation and inactivation and a high sensitivity to blockade by 
nickel (Soong et al., 1993). On the basis of these properties, together with cellular and subcellular distribution, Soong and coworkers (1993) have suggested that $\alpha_{1 \mathrm{E}}$ constitutes a novel member of the heterogeneous family of low voltage-activated Ca channels, although this notion is controversial (Ellinor et al., 1993; Zhang et al., 1993; Williams et al., 1994).

In this study, we show that consistent with native P-/Q-, N-, and L-type channels, peak whole-cell currents recorded from $\alpha_{1 \mathrm{~A}}, \alpha_{1 \mathrm{~B}}$, and $\alpha_{1 \mathrm{C}}$ were consistently smaller with $\mathrm{Ca}$ or $\mathrm{Sr}$ as the carrier ion compared with $\mathrm{Ba}$. A similar behavior was observed at the singlechannel level. In contrast, $\mathrm{Ca}$ or $\mathrm{Sr}$ substitution for Ba resulted in consistently larger peak whole-cell currents for $\alpha_{1 \mathrm{E}}$. At the singlechannel level, $\mathrm{Ba}, \mathrm{Ca}$, and $\mathrm{Sr}$ permeated $\alpha_{1 \mathrm{E}}$ equally, suggesting that this channel exhibits pronounced differences in its inner pore properties compared with the other Ca channel subtypes. Overall, the permeation properties observed with $\alpha_{1 \mathrm{E}}$ resemble those described for T-type Ca channels and support the notion that $\alpha_{1 \mathrm{E}}$ constitutes a novel member of a diverse family of low voltageactivated Ca channels.

\section{MATERIALS AND METHODS}

Isolation of Xenopus oocytes and nuclear injection of cloned Ca channel subunits. Stage V and VI oocytes were surgically removed from anesthetized adult Xenopus laevis and treated for 2-3 hr with $2 \mathrm{mg} / \mathrm{ml}$ collagenase (Type 1A; Sigma, St. Louis, MO) in a Ca-free medium. After a recovery period of 3-10 hr, nuclear injection was performed using $10 \mathrm{nl}$ of a 1:1:1 mix of cDNAs encoding rat brain Ca channel $\alpha_{1}$, $\alpha_{2}$, and $\beta$ subunits inserted into the pMT2 expression vector $(2.5 \mathrm{ng}$ of each cDNA). The cDNA constructs carrying the $\alpha_{1 \mathrm{~A}}, \alpha_{1 \mathrm{~B}}, \alpha_{1 \mathrm{C}}, \alpha_{1 \mathrm{E}}, \alpha_{2}$, and $\beta_{1 \mathrm{~b}}$ have been described previously (Soong et al., 1993; Tomlinson et al., 1993; Bourinet et al., 1994; Stea et al., 1994, 1995a). Before electrophysiological recording, oocytes were incubated at $19^{\circ} \mathrm{C}$ under gentle shaking on a rotating platform for 3-5 $\mathrm{d}$ in standard oocyte saline [(in mM): $100 \mathrm{NaCl}, 2 \mathrm{KCl}, 1.8 \mathrm{CaCl}_{2}, 1 \mathrm{MgCl}_{2}, 5 \mathrm{HEPES}$, at $\mathrm{pH}$ 7.5] containing $2.5 \mathrm{~mm}$ sodium pyruvate and $10 \mu \mathrm{g} / \mathrm{ml}$ gentamycin sulfate.

Electrophysiological recording. For oocytes, macroscopic currents were recorded using the two-electrode voltage-clamp technique with either a GeneClamp 500 amplifier or an Axoclamp 2A amplifier (Axon Instruments, Burlingame, CA). Acquisition and data analysis were performed using pCLAMP (v6.0) software (Axon Instruments). Leak currents and capacitive transients were subtracted using a $\mathrm{P} / 5$ procedure. Oocytes were placed in a $150 \mu \mathrm{l}$ recording chamber and superfused continuously with a solution containing (in $\mathrm{mm}$ ): either $5 \mathrm{Ba}(\mathrm{OH})_{2}, 5 \mathrm{Ca}(\mathrm{OH})_{2}$, or 5 $\mathrm{Sr}(\mathrm{OH})_{2}, 60$ TEA-OH, $25 \mathrm{NaOH}, 2 \mathrm{CsOH}, 5$ HEPES (titrated to pH 7.3 with methane sulfonic acid). $\mathrm{KCl}$-Agar bridges were used as ground electrodes to minimize any junction potential attributable to the change in ionic composition of the bath solution. Pipettes of typical resistance ranging from 0.5 to $1.5 \mathrm{M} \Omega$ were filled with $2.8 \mathrm{M} \mathrm{CsCl}, 0.2 \mathrm{M} \mathrm{CsOH}, 10$ mM HEPES, and $10 \mathrm{~mm}$ BAPTA-free acid. To record $\mathrm{Ca}$ channel activity accurately, the endogenous oocyte $\mathrm{Ca}$-activated $\mathrm{Cl}$ current was suppressed by injection of 10-30 $\mathrm{nl}$ of a solution containing $100 \mathrm{~mm}$ BAPTAfree acid and $10 \mathrm{~mm}$ HEPES ( $\mathrm{pH}$ titrated to 7.2 with $\mathrm{CsOH}$ ) using a third pipette connected to an electric microinjector. The estimated final intraoocyte BAPTA concentration was 2-5 mM. An effective exchange of the chamber solution was achieved within 1-2 sec, as judged by superperfusion of a solution containing $100 \mu \mathrm{M} \mathrm{Cd}$ and by monitoring the development of block. For each oocyte, solutions were switched from $\mathrm{Ba}$ to $\mathrm{Ca}$ to $\mathrm{Sr}$ and then again to $\mathrm{Ba}$ to eliminate possible errors arising from rundown during the time course of the experiment.

For concentration-conductance experiments, a different set of solutions was used because the hydroxide salts of $\mathrm{Ca}, \mathrm{Ba}$, and $\mathrm{Sr}$ are not soluble at physiological $\mathrm{pH}$ at concentrations greater than $\sim 50 \mathrm{~mm}$. In these cases we used $40 \mathrm{~mm} \mathrm{BaCl}_{2}$ or $40 \mathrm{~mm} \mathrm{CaCl}_{2}, 2 \mathrm{~mm} \mathrm{CsCl}, 36 \mathrm{~mm}$ TEA, $0.4 \mathrm{~mm}$ niflumic acid, $20 \mu \mathrm{M}$ 5-nitro-2-(3-phenylpropylamino) benzoic acid (NPPB), $5 \mathrm{~mm}$ HEPES, pH 7.6. In lower ionic strength solutions, sucrose was substituted for $\mathrm{Ca}$ or $\mathrm{Ba}$; in $100 \mathrm{~mm}$ solutions, TEA and $\mathrm{CsCl}$ were omitted. In these experiments current-voltage $(I-V)$ curves were acquired using a ramp stimulation from -100 to $100 \mathrm{mV}(\mathrm{dV} / \mathrm{dt}=$ $1 \mathrm{mV} / \mathrm{msec}$ ). This protocol permitted the acquisition of a complete $I-V$ relation in $2 \mathrm{sec}$ and allowed the study of a range of different ionic conditions on the same oocyte. There were no detectable differences between $I-V$ curves recorded using either the more typical increased steps to various potentials or the ramp protocol.

Macroscopic currents in HEK 293 cells were obtained by the whole-cell patch-clamp technique using an Axopatch 200A amplifier. The internal solution contained (in mM): $140 \mathrm{~N}$-methyl-D-glucamine (NMG)- $\mathrm{MeSO}_{3}$, 5 EGTA, $1 \mathrm{MgCl}_{2}, 4 \mathrm{MgATP}$, and $10 \mathrm{HEPES}, \mathrm{pH} 7.3$, adjusted with NMG. The external solution contained (in $\mathrm{mM}$ ): 130 NMG-aspartate, 1 $\mathrm{MgCl}_{2}, 10$ glucose, 10 4-aminopyridine, $10 \mathrm{HEPES}$, and $10 \mathrm{BaCl}_{2}$ or $\mathrm{CaCl}_{2}, \mathrm{pH} 7.3$, adjusted with NMG.

Single-channel recordings were performed on oocytes in the cellattached mode using a Gene Clamp 500 amplifier. The sampling frequency for acquisition was $5-10 \mathrm{kHz}$, and records were filtered at $1 \mathrm{kHz}$. After a short incubation (1-3 min) in a hyperosmotic medium to shrink the cell membrane, the vitelline envelope was removed manually from the oocyte. The membrane potential was reduced essentially to zero by placing the oocytes in a high potassium solution $(100 \mathrm{mM} \mathrm{KCl}, 10 \mathrm{~mm}$ EGTA, $2 \mathrm{mM} \mathrm{MgCl}_{2}$, and $10 \mathrm{~mm}$ HEPES, pH 7.3, with $\mathrm{NaOH}$ ). Sylgardcoated pipettes with resistances between 15 and $25 \mathrm{~m} \Omega$ were filled with a solution containing either $100 \mathrm{mM} \mathrm{BaCl}_{2}, 100 \mathrm{mM} \mathrm{CaCl}$, or $100 \mathrm{~mm}$ $\mathrm{SrCl}_{2}$, and $10 \mathrm{~mm} \mathrm{HEPES}, \mathrm{pH} 7.5$, with $\mathrm{NaOH}$. For recordings of $\alpha_{1 \mathrm{C}}, 5$ $\mathrm{mm}$ Bay K8644 was included in the pipette.

Transient expression in HEK cells. HEK 293 cells were transiently transfected as described previously (Dhallan et al., 1990), using $10 \mu \mathrm{g}$ each of $\alpha_{1 \mathrm{E}}$ and $\beta_{2 \mathrm{a}}$ cDNAs subcloned into the vector pGW1H (British Biotechnology, Abingdon, UK).

Data analysis and curve fitting. Macroscopic $I-V$ relations were fitted using the equation:

$$
I=G \times\left(V-E_{\mathrm{rev}}\right) /\left(1+\exp \left\{\left(V-V_{0.5}\right) / K\right\}\right)
$$

where $I$ is the current at the potential $V, G$ is the maximum slope conductance, and $E_{\text {rev }}, V_{0.5}$, and $K$ are the reversal potential, the potential of half activation, and the slope factor of the activation curve, respectively. Single-channel conductances were obtained from linear regression through open single-channel $I-V$ relationships. Unless stated otherwise, error bars represent SE.

Materials. Drugs were purchased from Sigma, except for BayK 8644 and NPPB, which were purchased from RBI (Natick, MA), and for $\mathrm{Sr}(\mathrm{OH})_{2}$, which was a kind gift from Dr. Joël Nargeot.

\section{RESULTS}

\section{$\alpha_{1 E}$ channels exhibit permeation properties distinct from other $\mathrm{Ca}$ channel subtypes}

Figure 1 illustrates the whole-cell properties of four major rat brain Ca channel subtypes, $\alpha_{1 \mathrm{~A}}, \alpha_{1 \mathrm{~B}}, \alpha_{1 \mathrm{C}}$, and $\alpha_{1 \mathrm{E}}$ (coexpressed with $\alpha_{2}$ and $\beta_{1 \mathrm{~b}}$ subunits), using $\mathrm{Ba}, \mathrm{Sr}$, or $\mathrm{Ca}$ as the charge carriers. For each channel type, switching the external solution from $\mathrm{Ba}$ to $\mathrm{Sr}$ to $\mathrm{Ca}$ induced a depolarizing shift of the $I-V$ relation toward more depolarized potentials. Furthermore, at least for $\alpha_{1 \mathrm{C}}$, the steepness of the activation curve appeared reduced, consistent with that observed for native L-type Ca channels (Byerly et al., 1985). Of particular note, both the peak currents and the maximum slope conductances were differentially affected among various neuronal $\mathrm{Ca}$ channel subtypes. Although the peak currents of $\alpha_{1 \mathrm{~A}}, \alpha_{1 \mathrm{~B}}$, and $\alpha_{1 \mathrm{C}}$ were all significantly larger in $\mathrm{Ba}$ than in $\mathrm{Sr}$ or $\mathrm{Ca}\left(I_{\mathrm{Ba}}>I_{\mathrm{Sr}}>I_{\mathrm{Ca}}\right), \alpha_{1 \mathrm{E}}$ showed larger currents in $\mathrm{Sr}$ compared with $\mathrm{Ca}$ or $\mathrm{Ba}\left(I_{\mathrm{Sr}}>I_{\mathrm{Ca}}>I_{\mathrm{Ba}}\right)$. Although switching the type of permeant ion also appeared to result in changes in the reversal potential, producing a more positive reversal potential with $\mathrm{Ca}$ as the charge carrier compared with $\mathrm{Sr}$ and $\mathrm{Ba}\left(E_{\mathrm{rev}, \mathrm{Ca}}>E_{\mathrm{rev}, \mathrm{Sr}}>E_{\mathrm{rev}, \mathrm{Ba}}\right)$, we did not attempt to estimate permeability ratios from the measured reversal potential values, because the intracellular divalent cation concentration could not be controlled precisely.

If changes in reversal potential and half-activation potential differed in their absolute magnitudes, the peak current ratios would be a poor indication of the true conductance ratio. To circumvent this issue, we used the slope of the $I-V$ relation on the 


$$
\alpha_{1 A}+\alpha_{2}+\beta_{1 b}
$$

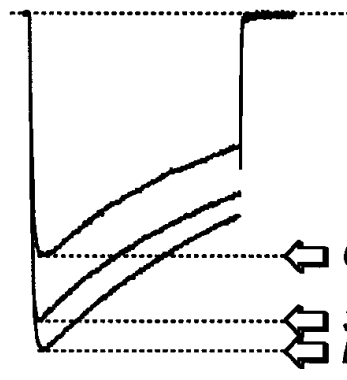

$100 \mathrm{mSec}$

$$
\alpha_{1 c}+\alpha_{2}+\beta_{1 b}
$$
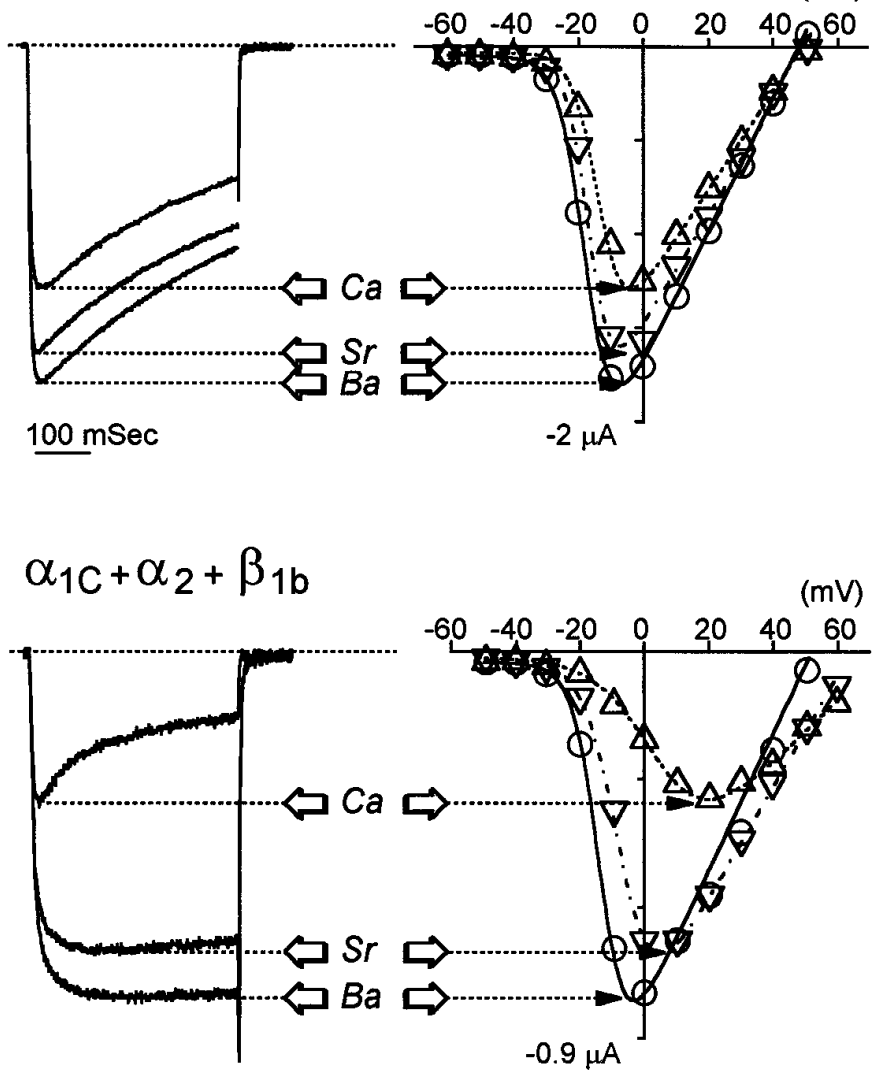

$$
\alpha_{1 \mathrm{~B}}+\alpha_{2}+\beta_{1 \mathrm{~b}}
$$

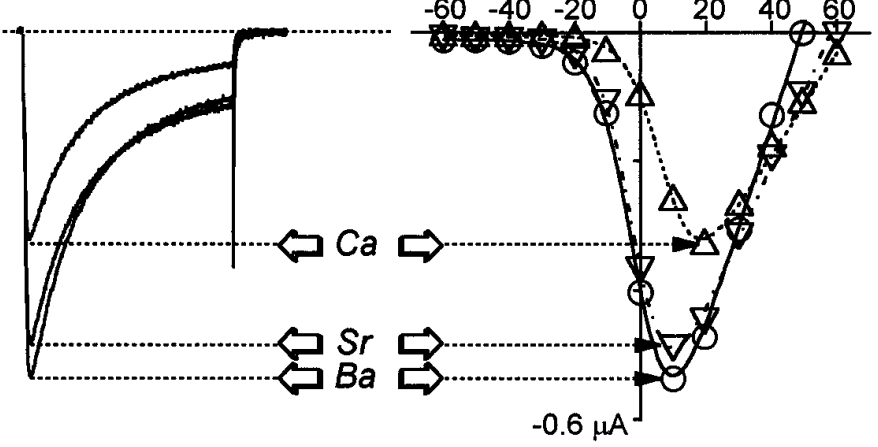

$\alpha_{1 E}+\alpha_{2}+\beta_{1 b}$

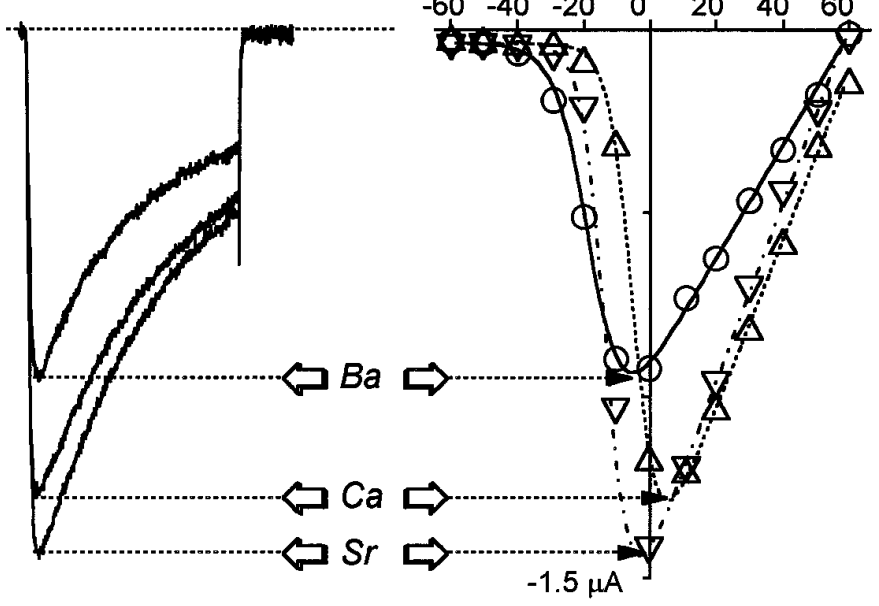

Figure 1. Comparison of macroscopic currents carried by $5 \mathrm{~mm} \mathrm{Ba}, \mathrm{Ca}$, or Sr. Current traces obtained at the peak of the $I-V$ relations for $\alpha_{1 \mathrm{~A}}, \alpha_{1 \mathrm{~B}}, \alpha_{1 \mathrm{C}}$, and $\alpha_{1 \mathrm{E}}$ (coexpressed with $\alpha_{2}$ and $\beta_{1 \mathrm{~b}}$ ) are presented with their respective $I-V$ relations. $I-V$ relations were fitted as described in Materials and Methods. Note that Ba produces the largest currents through $\alpha_{1 \mathrm{~A}}, \alpha_{1 \mathrm{~B}}$, and $\alpha_{1 \mathrm{C}}$, but the smallest currents through $\alpha_{1 \mathrm{E}}$ channels. Also note the pronounced Ca-dependent inactivation for $\alpha_{1 \mathrm{C}}$.

plateau of the activation curve (i.e., the maximum slope conductance, $G)$ as an indication of the ability of the carrier ion to permeate the channel. As shown in Figure $2 a$, $\mathrm{Ca}$ and $\mathrm{Sr}$ produced a larger conductance compared to Ba for $\alpha_{1 \mathrm{E}}$, whereas the order was reversed for the other channel isoforms (for $\alpha_{1 \mathrm{~A}}, \alpha_{1 \mathrm{~B}}$, and $\alpha_{1 \mathrm{C}}: G_{\mathrm{Ba}}>G_{\mathrm{Sr}}>G_{\mathrm{Ca}}$ ). A comparison with the peak ratios (Fig. $2 b$ ) revealed a similar profile, consistent with the observation that the shifts in reversal potential and the shifts in half-activation voltage that occur when switching from $\mathrm{Ba}$ to $\mathrm{Ca}$ (or $\mathrm{Sr}$ ) were of similar magnitude.

\section{Ca channel permeation characteristics are determined by the $\alpha_{1}$ subunit}

The coexpression of ancillary $\mathrm{Ca}$ channel subunits modulates several biophysical properties of cloned Ca channel $\alpha_{1}$ subunits (for review, see Stea et al., 1995b). To determine whether $\alpha_{2}$ and $\beta$ subunits affected permeation, we examined the conductance profiles of $\alpha_{1 \mathrm{~A}}$ and $\alpha_{1 \mathrm{E}}$ alone (both of these channel types result in high levels of expression in oocytes in the absence of ancillary subunits) (Soong et al., 1993; Stea et al., 1994). Figure 3 shows that no significant differences in the response to switching the type of permeant ion were observed when $\alpha_{2}$ and $\beta$ subunits were omitted. All of the changes induced by the $\mathrm{Ba}-\mathrm{Ca}-\mathrm{Sr}$ substitutions described in Figures 1 and 2 were maintained, including the unique profile of the $\alpha_{1 \mathrm{E}}$ channel. Taken together, these data suggest that the basic permeation properties are intrinsic to the $\alpha_{1}$ subunit and are not significantly affected by coexpression with $\alpha_{2}$ or $\beta$ subunits. Furthermore, the permeation differences between $\alpha_{1 \mathrm{E}}$ and the other channel types is indicated to be an inherent property of the $\alpha_{1 \mathrm{E}}$ protein.

\section{Dependence of the different $\alpha_{1}$ channels on $\left[\mathrm{Ba}^{2+}\right]_{0}$ and $\left[\mathrm{Ca}^{2+}\right]_{\mathrm{o}}$}

To characterize further the permeation characteristics of the $\mathrm{Ca}$ channel isoforms, we recorded concentration-conductance relations for the four $\mathrm{Ca}$ channel subtypes in both $\mathrm{Ba}$ and $\mathrm{Ca}$ (Fig. 4). Increasing the external concentration of either cation progressively increased the whole-cell conductance. The conductance subsequently leveled off at higher concentrations and was consistent with the existence of one or more saturable binding sites for both $\mathrm{Ca}$ and $\mathrm{Ba}$ within the pore. In Figure 4, the data obtained in $\mathrm{Ba}$ and $\mathrm{Ca}$ are scaled and superimposed, revealing that the binding sites along the permeation pathway become similarly saturated with either $\mathrm{Ba}$ or $\mathrm{Ca}$ as the carrier ion for each of the 


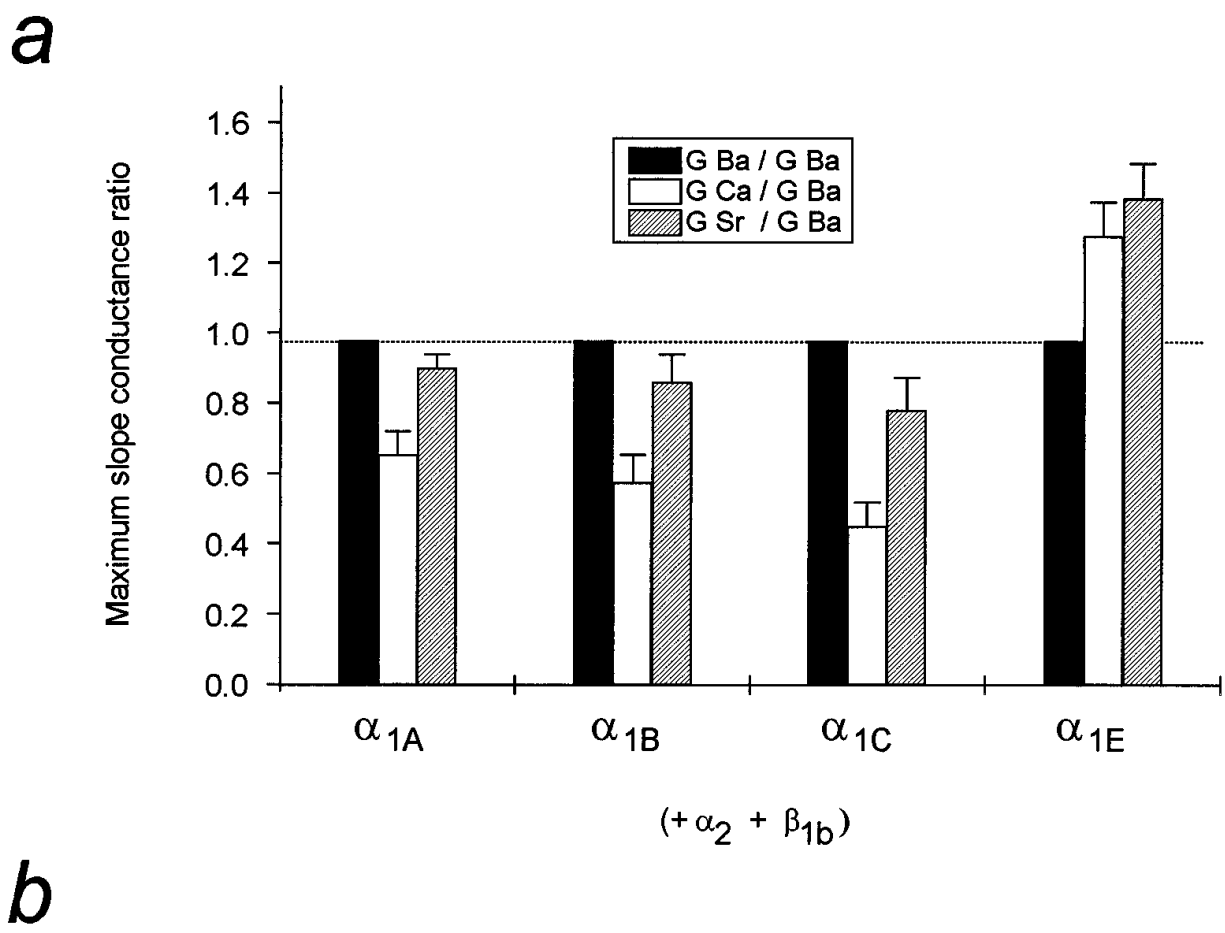

Figure 2. Summary of the conductance properties of the different channels. Apparent maximum slope conductances obtained from fits to individual $I-V$ relations are compared in $a$. Values are presented in the form of conductance ratios $\left(G_{\text {ion }} / G_{\mathrm{Ba}}\right)$. $b$, The peak current values from the same experiments, normalized to those seen in $\mathrm{Ba}\left(I_{\max (i o n)}\right)$ $\left.I_{\max (\mathrm{Ba})}\right)$. Note the different permeation profile of the $\alpha_{1 \mathrm{E}}$ channel. Error bars are SE based on 5-14 determinations.

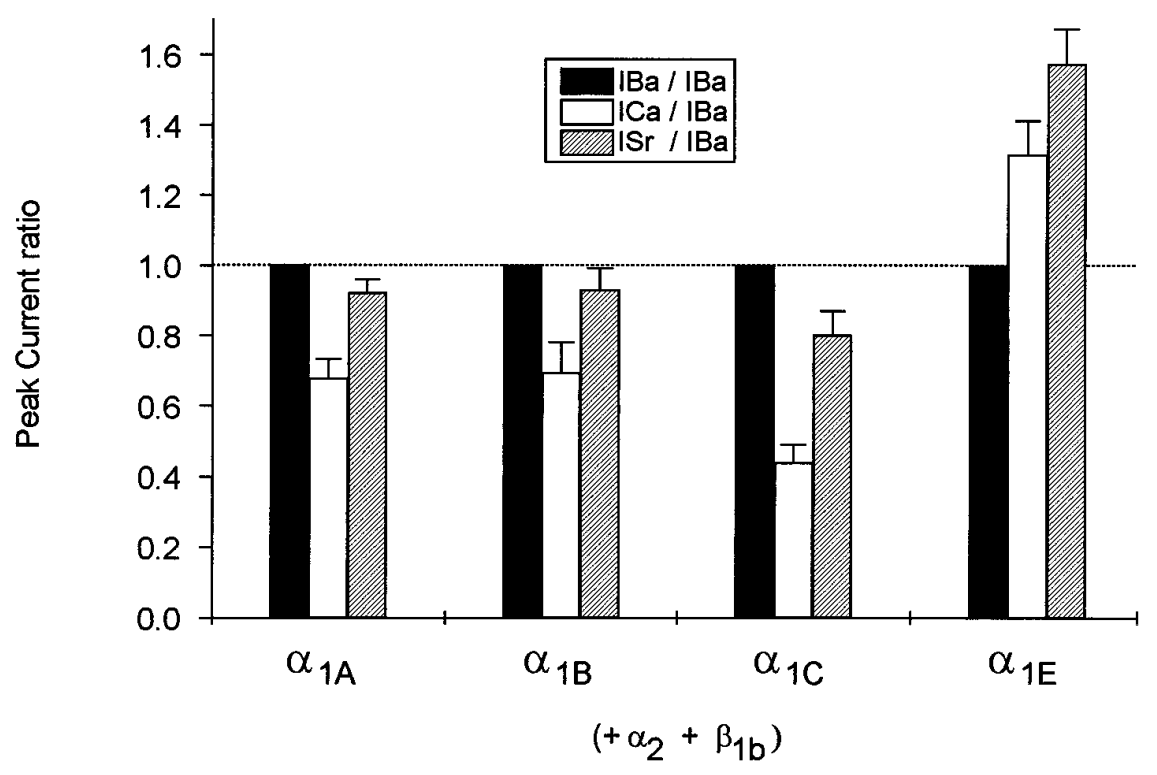

channel subtypes. A pronounced difference, however, becomes apparent on comparison of $\alpha_{1 \mathrm{C}}$ with the other channel subtypes. The concentration-conductance relation rose more steeply for $\alpha_{1 \mathrm{C}}$ and saturated at a lower concentration (Fig. 4), suggesting that the divalent binding sites in the pore of $\alpha_{1 \mathrm{C}}$ exhibit a higher affinity for permeating ions relative to the other channel types. Because the saturation for $\alpha_{1 \mathrm{E}}$ channels was similar to that for $\alpha_{1 \mathrm{~A}}$ and $\alpha_{1 \mathrm{~B}}$, a difference in affinity for a putative divalent binding site as the reason for the permeation differences in $\mathrm{Ba}$ and $\mathrm{Ca}$ can be excluded.

\section{Unitary current as a function of the permeant ion}

The maximum slope conductance $G$ is a product of the singlechannel conductance $(g)$, the number of channels $(n)$ and their open probability $(\mathrm{Po})$. To determine whether the dependence of the whole-cell conductance was attributable to a change in $g$, we examined the single-channel conductances of the four $\mathrm{Ca}$ channel subtypes in both $\mathrm{Ba}$ and $\mathrm{Ca}$ (and $\mathrm{Sr}$ in the case of $\alpha_{1 \mathrm{E}}$ ). Figure 5 shows that the single-channel conductances of $\alpha_{1 \mathrm{C}}$, $\alpha_{1 \mathrm{~A}}$, and $\alpha_{1 \mathrm{~B}}$ all were reduced notably when Ca replaced $\mathrm{Ba}$. In contrast, the single-channel conductance of $\alpha_{1 \mathrm{E}}$ was similar in $\mathrm{Ba}, \mathrm{Ca}$, or $\mathrm{Sr}$. The two most extreme cases are illustrated in Figure $5 b$, with a side-by-side comparison of the unitary conductance-voltage relations for $\alpha_{1 \mathrm{E}}$ and $\alpha_{1 \mathrm{C}}$ and single-channel records at a test potential of $0 \mathrm{mV}$. Consistent with the wholecell data, the single-channel amplitude of currents carried by $\alpha_{1 \mathrm{C}}$ channels was about half of that seen with $\mathrm{Ba}$. For $\alpha_{1 \mathrm{E}}$, the unitary currents were nearly identical with either $\mathrm{Ba}, \mathrm{Ca}$, or $\mathrm{Sr}$. These data indicate that the increases in slope conductance associated with $\mathrm{Sr}$ or $\mathrm{Ca}$ substitution for $\mathrm{Ba}$ were more likely attributable to an increase in plateau open probability than to 


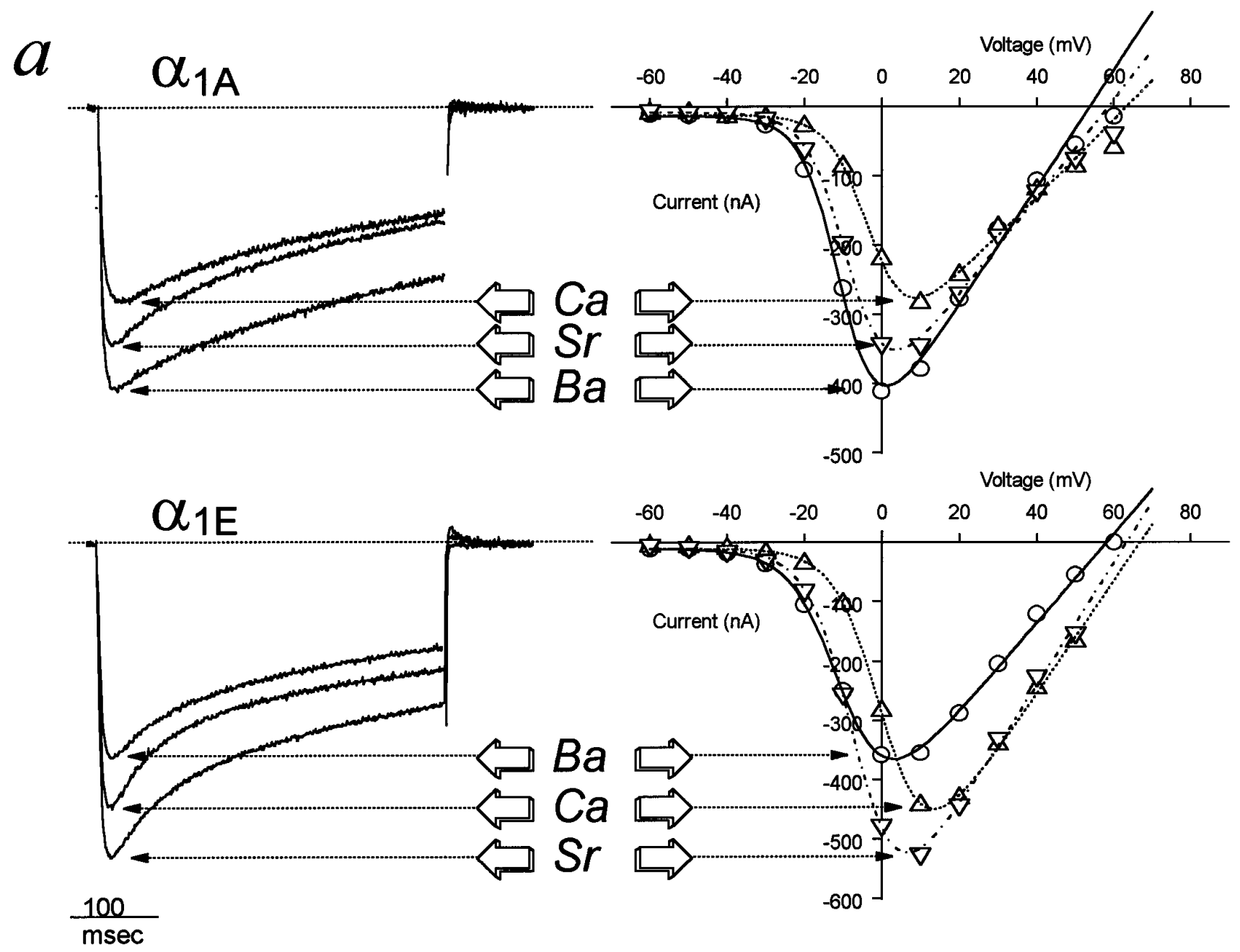

\section{$b$}
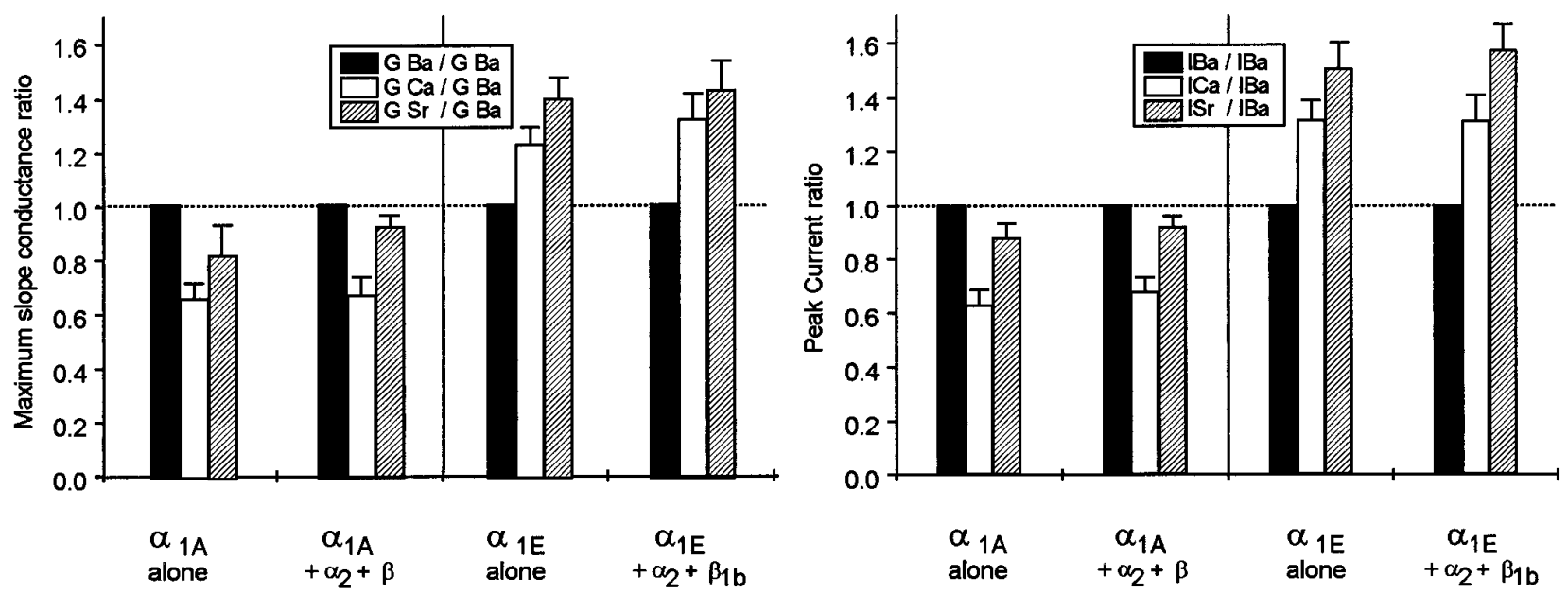

Figure 3. Comparison of macroscopic $\mathrm{Ba}, \mathrm{Ca}$, and $\mathrm{Sr}$ currents through $\alpha_{1 \mathrm{~A}}$ and $\alpha_{1 \mathrm{E}}$ in the absence of ancillary subunits. $a$, Peak current traces with their respective current-voltage relationships as described in Figure $1(\mathrm{O}, \mathrm{Ba} ; \Delta, \mathrm{Ca} ; \nabla, \mathrm{Sr}) . b$, Comparison of the maximum slope conductance ratios $\left(G_{\text {ion }} / G_{\mathrm{Ba}}\right)$ and peak current ratios $\left(I_{\max (\mathrm{ion})} / I_{\max (\mathrm{Ba})}\right)$ in the presence and absence of $\alpha_{2}$ and $\beta_{1 \mathrm{~b}}$ subunits. Note that the ancillary subunits do not significantly affect the permeation properties of the channels. Error bars are SE on 5-12 determinations. 

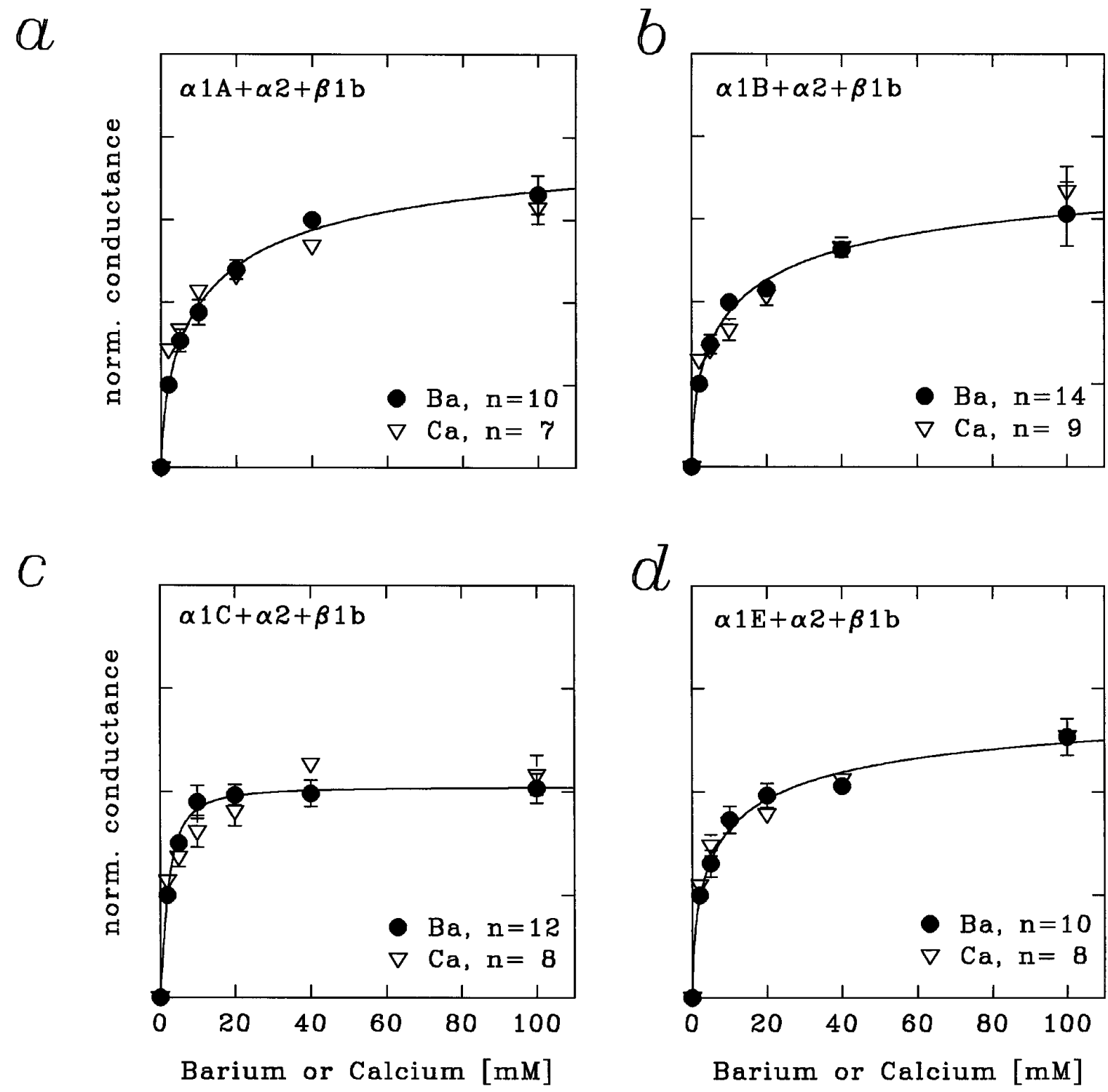

Figure 4. Concentration-conductance relations obtained for the four $\alpha_{1}$ subunits coexpressed with $\beta_{1 \mathrm{~b}}$ and $\alpha_{2}$. The data were normalized to 1 at an ion concentration of $2 \mathrm{~mm}$ and superimposed. Note that the conductance depends similarly on both $\mathrm{Ba}$ and $\mathrm{Ca}$ concentration for each of the Ca channel subtypes. The $\alpha_{1 \mathrm{C}}$ channels seem to differ from the other subtypes in that the current saturates at lower concentrations. The data were obtained from fits to macroscopic $I-V$ relations. Error bars indicate SE; the solid lines are a smooth approximation of the Ba data based on the Hill equation.

a change in single-channel conductance. This notion is supported by a preliminary analysis of steady-state activation at the single-channel level (not shown) and is consistent with previous studies (Shuba et al., 1991). Overall, the single-channel data support the uniqueness of the permeation properties of $\alpha_{1 \mathrm{E}}$ as compared with the other neuronal $\mathrm{Ca}$ channel subtypes.

\section{The distinct properties of $\alpha_{1 \mathrm{E}}$ are not dependent on the expression system}

To exclude contributions of the amphibian cellular environment to the distinct properties of $\alpha_{1 \mathrm{E}}$, we investigated the whole-cell properties of $\alpha_{1 \mathrm{E}}$ transiently expressed in human embryonic kidney cells (HEK 293). In this series of experiments, the $\alpha_{1 \mathrm{E}}$ subunit was coexpressed with $\beta_{2 \mathrm{a}}$ to slow inactivation, thereby maximizing resolution of peak currents. As expected from the $\mathrm{Ca}$-induced shift in $V_{0.5}$, macroscopic $\mathrm{Ba}$ currents were initially larger than Ca currents at modest depolarizations $(-15 \mathrm{mV})$, but $\mathrm{Ca}$ currents exceed Ba currents at stronger depolarization (to +5 and $+25 \mathrm{mV}$ ). A comparison of Figure 6 and Figure 1 shows a similar $\alpha_{1 \mathrm{E}}$ dependence on permeant ion type in both oocytes and mammalian cells. These results indicate that the distinctive properties of $\alpha_{1 \mathrm{E}}$ are attributable to the intrinsic permeation and gating properties of the channel and are independent of the expression system.

\section{DISCUSSION}

\section{$\alpha_{1 E}$ permeation properties resemble those of low- threshold Ca channels}

In contrast with the higher threshold $\alpha_{1 \mathrm{~A}}, \alpha_{1 \mathrm{~B}}$, and $\alpha_{1 \mathrm{C}} \mathrm{Ca}$ channels, the biophysical and pharmacological properties of $\alpha_{1 \mathrm{E}}$ do not exactly match any of the established classes of native Ca channels. That $\alpha_{1 \mathrm{E}}$ 


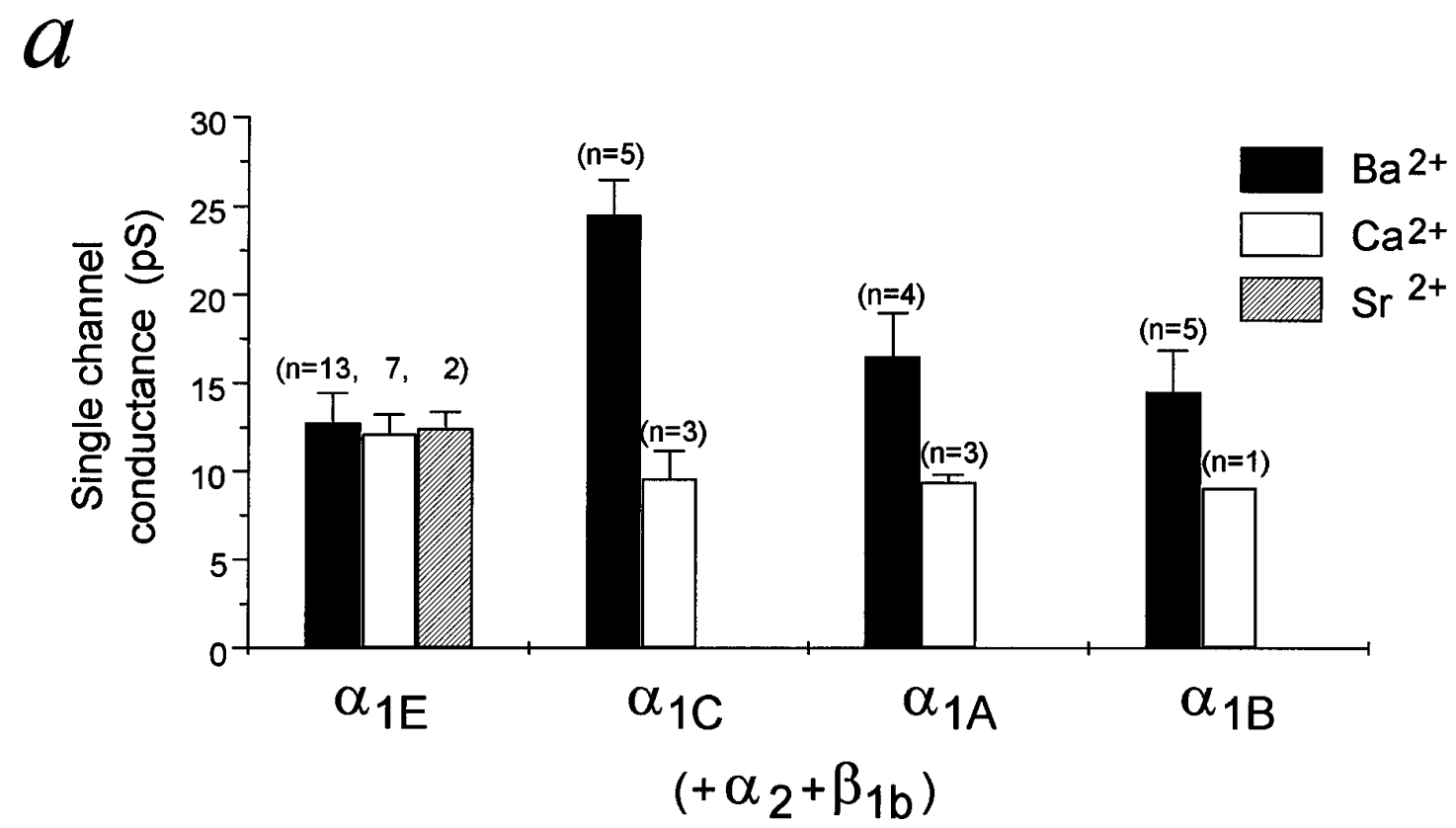

$b$
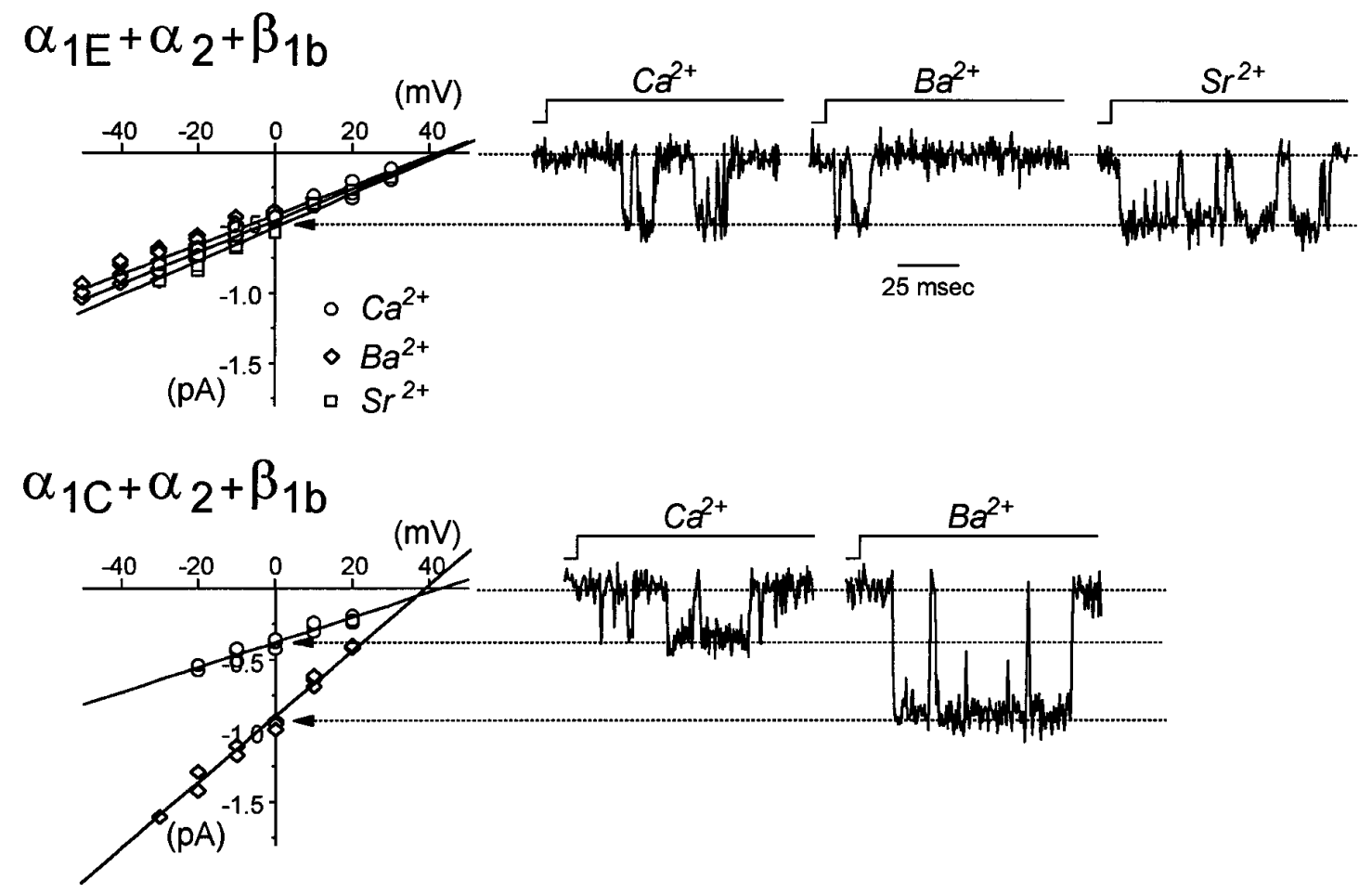

Figure 5. Dependence of the single-channel conductance on the type of external permeant ion. The histogram in $a$ summarizes the results obtained with the four $\alpha_{1}$ subunits coexpressed $\alpha_{2}$ and $\beta_{1 \mathrm{~b}}$. The conductance of $\alpha_{1 \mathrm{E}}$ is not significantly different with $100 \mathrm{~mm} \mathrm{Ba,} \mathrm{Ca,} \mathrm{or} \mathrm{Sr} \mathrm{as} \mathrm{permeant} \mathrm{ion,}$ whereas $\alpha_{1 \mathrm{C}}, \alpha_{1 \mathrm{~A}}$, and $\alpha_{1 \mathrm{~B}}$ exhibit larger conductances in Ba than in Ca. Error bars indicate SD. $b, \alpha_{1 \mathrm{E}}$ and $\alpha_{1 \mathrm{C}} I-V$ relations and current traces evoked by a step depolarization from -100 to $0 \mathrm{mV}$. Solid lines in the current-voltage relations are linear regressions through the data.

represents a novel type of neuronal mid- to low-threshold Ca channel that is distinct from the commonly accepted T-type channel has been a subject of controversy (Soong et al., 1993; Zhang et al., 1993; Williams et al., 1994). It has been suggested that the $\alpha_{1 \mathrm{E}}$ isoform from human brain encodes a high voltage-threshold channel (Williams et al., 1994). Similarly, an $\alpha_{1 \mathrm{E}}$ homolog from the marine ray nervous system (Ellinor et al., 1993) exhibits $I-V$ characteristics more similar to high voltage-threshold $\mathrm{Ca}$ channels and has been corre- 


\section{$\alpha_{1 E}+\beta_{2 a}$}
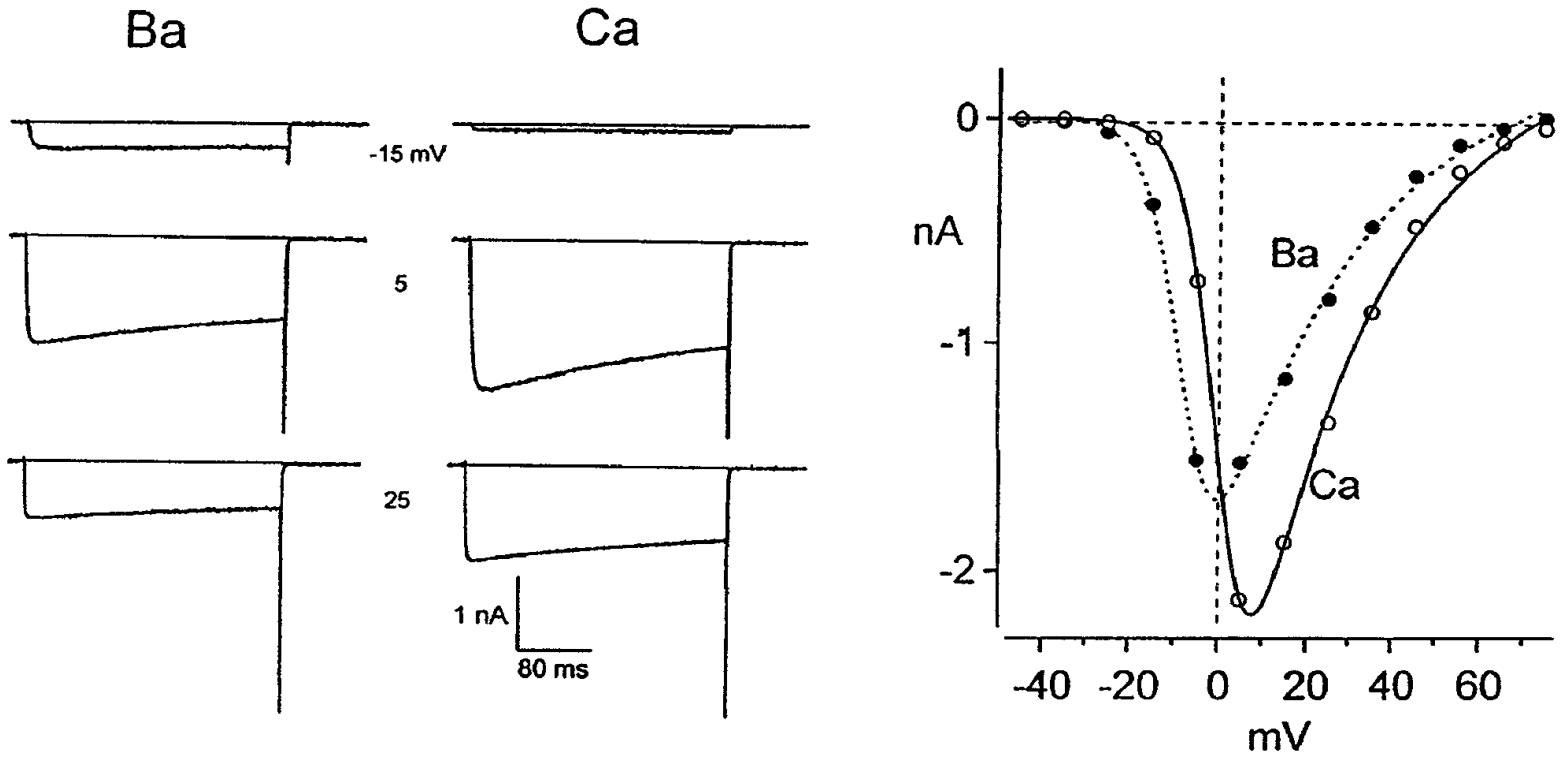

Figure 6. Comparison of Ba and Ca whole-cell currents of $\alpha_{1 \mathrm{E}}$ as expressed in HEK 293 cells. Left, Whole-cell Ba and Ca currents elicited by the indicated test depolarizations from a holding potential of $-90 \mathrm{mV}$. The tail potential is $-80 \mathrm{mV}$. Records have been leak-subtracted by a $\mathrm{P} / 8$ algorithm, filtered at $2 \mathrm{kHz}$ (4-pole Bessel filter), and sampled at $10 \mathrm{kHz}$. Right, Peak current versus test voltage relation. Smooth curves are drawn by eye. Series resistance of $5 \mathrm{M} \Omega$, compensated by $70 \%$; cell capacitance of $34 \mathrm{pF}$. All recordings at room temperature.

lated with a rat granular cell Ca current resistant to dihydropyridines, $\omega$-conotoxin GVIA, and $\omega$-agatoxin IVA (termed "R-type"; Zhang et al., 1993). It has been argued that the time course of inactivation seen with transiently expressed $\alpha_{1 \mathrm{E}}$ channels is slow compared with that of native T-type channels. When RNA fractions presumably encoding for T-type channels from thalamic neurons are injected into Xenopus oocytes, however, the resulting waveform is also slowed compared with the channels in their native environment (Dzhura et al., 1994), suggesting that gating kinetics may in some instances be a poor diagnostic for identifying native counterparts to cloned $\mathrm{Ca}$ channels. The rat brain $\alpha_{1 \mathrm{E}}$ channel shows two pronounced differences compared with the residual R-type current (Zhang et al., 1993). First, unlike $\alpha_{1 \mathrm{E}}$ (de Leon et al., 1995), the R-type current described by Zhang and coworkers (1993) exhibits a faster rate of inactivation with $\mathrm{Ca}$ as the charge carrier. We could not detect a similar effect on $\alpha_{1 \mathrm{E}}$ channels in either oocytes or HEK cells, although this property is readily observed for $\alpha_{1 \mathrm{C}}$ channels expressed in these two systems (Charnet et al., 1994; de Leon et al., 1995). Second, the permeation profile of the residual R-type current indicates a higher permeation for Ba over Ca (Zhang et al., 1993) and is significantly different from that reported here for $\alpha_{1 \mathrm{E}}$.

As suggested by Soong and coworkers (1993), our results provide further support for the notion that $\alpha_{1 \mathrm{E}}$ possesses properties consistent with a subset of neuronal low-threshold $\mathrm{Ca}$ channels. As summarized in Table 1, most low-threshold (T-type) Ca channels have been shown to carry larger whole-cell currents with $\mathrm{Ca}$ compared with $\mathrm{Ba}$. This effect is observed in various cell types, including atrial and ventricular myocytes (Bean, 1985, Nilius et al.,

Table 1. Relative $\mathrm{Ca}^{2+}, \mathrm{Ba}^{2+}$, and $\mathrm{Sr}^{2+}$ conduction through native and cloned $\mathrm{Ca}^{2+}$ channel subtypes

\begin{tabular}{lllll} 
Native type & $\mathrm{T}$ & $\mathrm{L}$ & $\mathrm{N}$ & $\mathrm{P} / \mathrm{Q}$ \\
\hline$I_{\mathrm{Ca}} / I_{\mathrm{Ba}}$ & $1-1.8$ & $0.2-0.6$ & $0.6-0.8$ & 0.5 \\
& $(1,2,3,4,5,6,7,8)^{a}$ & $(1,5,6,7,9,10,11)^{a}$ & $(1,13)^{a}$ & $(14)^{a}$ \\
$I_{\mathrm{Sr}} / I_{\mathrm{Ba}}$ & $1.5-1.9$ & $0.6-0.8$ & 0.7 & $(15)^{a}$ \\
& $(2,4,8)^{a}$ & $(12,13)^{a}$ & $(13)^{a}$ & $?$ \\
\hline
\end{tabular}

\begin{tabular}{lllll} 
Expressed cDNA & $\alpha_{1 \mathrm{E}}$ & $\alpha_{1 \mathrm{C}}$ & $\alpha_{1 \mathrm{~B}}$ & $\alpha_{1 \mathrm{~A}}$ \\
\hline$I_{\mathrm{Ca}} / I_{\mathrm{Ba}}$ & 1.3 & 0.4 & 0.7 & 0.7 \\
$I_{\mathrm{Sr}} / I_{\mathrm{Ba}}$ & $(16)^{a}$ & $(16)^{a}$ & $(16)^{a}$ & $(16)^{a}$ \\
& 1.5 & 0.8 & 0.9 & 0.9 \\
& $(16)^{a}$ & $(16)^{a}$ & $(16)^{a}$ & $(16)^{a}$
\end{tabular}

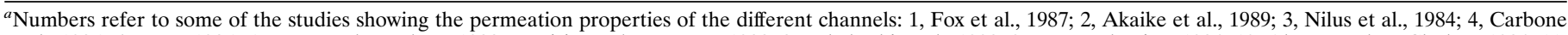

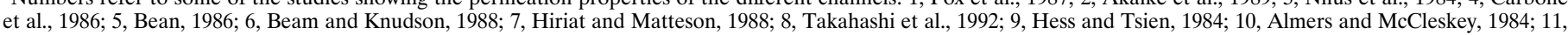
Neveu et al., 1994; 12, Hagiwara and Ohmori, 1982; 13, Kasai and Neher, 1992; 14, Regan, 1991; 15, Zhang et al., 1993; 16, this study. 
1986), skeletal and smooth muscle cells (Beam and Knudson, 1988, Neveu et al., 1994), pancreatic B cells (Hiriat and Matteson, 1988), and both peripheral and central neurons (Carbone and Lux, 1987; Fox et al., 1987; Akaike et al., 1989; Takahashi et al., 1991). An exception to this general trend is an unusual T-type channel from the reticular nucleus of the thalamus, which exhibits larger currents in Ba than in Ca (Huguenard and Prince, 1992). Overall, at both the whole-cell and single-channel levels, our results with $\alpha_{1 \mathrm{E}}$ are consistent with those reported for the majority of native low voltage-threshold channels.

At the macroscopic level, Williams et al. (1994) reported that the human $\alpha_{1 \mathrm{E}}$ isoform ( $>95 \%$ identical to the rat brain subtype) displayed a more prominent activity in $\mathrm{Ba}$ rather than in $\mathrm{Ca}$. The difference may be attributable to the small differences in amino acid sequence between the species-specific isoforms. Alternatively, as a significant degree of rundown of $\alpha_{1 \mathrm{E}}$ currents occurs, the magnitude of the whole currents may seem to decrease in some cells if the external solutions are not applied cyclically (e.g., $\mathrm{Ba}$ to $\mathrm{Ca}$ and then back to $\mathrm{Ba}$; not shown). In our experiments, we minimized the possibility of induced errors arising from rundown by performing a cyclic application of divalent ions (see Materials and Methods).

For $\alpha_{1 \mathrm{E}}$, the whole-cell current magnitude varied with the relative ratio $\mathrm{Sr}>\mathrm{Ca}>\mathrm{Ba}$. In contrast, the single-channel conductances were virtually identical with either $\mathrm{Ba}, \mathrm{Ca}$, or $\mathrm{Sr}$. On the basis of a preliminary analysis of the open probability at the plateau of the activation curve, our results suggest that the higher maximum slope conductances obtained in $\mathrm{Sr}$ and $\mathrm{Ca}$ are attributable to an increase in the open probability of the channel (see $\alpha_{1 \mathrm{E}}$ single-channel traces in Fig. $5 b$ ) and a reduction in the number of blank sweeps (not shown). A similar dependence of open probability on the type of permeant ion has been described previously for native low-threshold channels (McDonald et al., 1994).

\section{Ca substitution for Ba differentially affects neuronal Ca channels}

A major goal of this study was to determine permeation characteristics of the four major classes of cloned neuronal Ca channels under identical conditions. A number of previous studies indicate that native high voltage-threshold $\mathrm{Ca}$ channels carry larger currents with $\mathrm{Ba}$ as the permeant ion as compared with $\mathrm{Ca}$ or $\mathrm{Sr}$ (see Table 1). The most detailed descriptions of divalent cation permeation has been carried out for native L-type Ca channels from both heart and skeletal muscle (Almers and McCleskey, 1984; Hess et al., 1986; Yue and Marban, 1990; McDonald et al., 1994). Current permeation models assume double occupancy of the pore and electrostatic repulsion between both ions (Almers and McCleskey, 1984; Hess and Tsien, 1984) and suggest that Ca ions bind more tightly within the pore than $\mathrm{Ba}$ ions, which results in a smaller current amplitude. This feature seems to be common among all L-type Ca channels; however, the absolute value of the conductance ratio in $\mathrm{Ba}$ and $\mathrm{Ca}$ shows some variability among channels from different tissues (e.g., cardiac vs skeletal muscle) (Beam and Knudson, 1988) and between distinct populations of L-type channels present in a same tissue (e.g., in aortic myocytes) (Neveu et al., 1994). There have also been reports demonstrating that both N-type (Fox et al., 1987; Kasai and Neher, 1992) and P-type (Regan, 1991) channels carry larger currents in Ba compared with $\mathrm{Ca}$. Our results showing increased whole-cell Ba currents for $\alpha_{1 \mathrm{~A}}, \alpha_{1 \mathrm{~B}}$, and $\alpha_{1 \mathrm{C}}$ support these studies. Similar to that observed with native cardiac and neuronal L-type channels, Ca substitution for $\mathrm{Ba}$ also increased the rate of inactivation and seemed to decrease the steepness of the activation curve of the $\alpha_{1 \mathrm{C}}$ L-type channel (Byerly et al., 1985; Charnet et al., 1994; Galli et al., 1994; Imredy and Yue, 1994; Neely et al., 1994; Perez-Reyes et al., 1994; de Leon et al., 1995). Although it is possible that some of the effects observed at the whole-cell level are attributable to altered channel kinetics (McDonald et al., 1994), the singlechannel records support the notion that the dependence of the whole-cell conductance on the type of permeant ion is an intrinsic property of the permeation pathway (all of the high voltageactivated subtypes studied here exhibited smaller single-channel conductances when the permeant ion was switched from $\mathrm{Ba}$ to $\mathrm{Ca})$. The $\alpha_{1 \mathrm{E}}$ channels display a unique dependence of nickel pore block on the type of permeant ion compared with $\alpha_{1 \mathrm{~A}}$ and $\alpha_{1 \mathrm{C}}$ channels, consistent with the distinct permeation properties observed with $\alpha_{1 \mathrm{E}}$ (Zamponi et al., 1996).

\section{Implications for models of $\mathbf{C a}$ channel permeation}

Concentration-conductance curves obtained for the four different types of $\mathrm{Ca}$ channels revealed two additional qualitative features of Ca channels. First, with the concentration-conductance curves scaled, the data obtained in $\mathrm{Ba}$ and $\mathrm{Ca}$ superimposed for each of the $\mathrm{Ca}$ channel isoforms. Second, the concentration-conductance curves obtained for $\alpha_{1 \mathrm{C}}$ appeared steeper than those of the other channel subtypes (at $40 \mathrm{~mm}$, a concentration that produces only a $70 \%$ saturation of each $\alpha_{1 \mathrm{~A}}, \alpha_{1 \mathrm{~B}}$, and $\alpha_{1 \mathrm{E}}$, currents through $\alpha_{1 \mathrm{C}}$ are essentially saturated). Although the multi-ion nature of the pore precludes us from estimating a precise $K_{\mathrm{d}}$ value for binding of permeant ions to proposed intrapore sites, these qualitative observations suggest a stronger affinity of both $\mathrm{Ca}$ and $\mathrm{Ba}$ ions for the pore of $\alpha_{1 C}$ than with the remaining channel subtypes. Second, the results also suggest that each of the channel types becomes similarly saturated with either ion.

The half-saturation concentration is mainly dependent on the depth of the energy wells in the pore, whereas the maximal conductance at saturating concentrations depends predominantly on the height of the exit barrier toward the cytoplasmic side (Hille, 1992). We observed an effect of the type of permeant ion only on maximal conductance, and the data suggest that the unique properties observed for $\alpha_{1 \mathrm{E}}$ may be attributable to the distinct properties of its exit barrier. Amino acids in the poreforming regions of the $\mathrm{Ca}$ channel isoforms are highly conserved across the Ca channel isoforms (for review, see Stea et al., 1995b). It has been proposed recently that four glutamate residues in the pore are the most crucial determinant of permeation (Tang et al., 1993; Yang et al., 1993). The glutamates are thought to cooperate in forming a high-affinity interaction between the channel and permeating ions (Ellinor et al., 1995). Electrostatic repulsion between two $\mathrm{Ca}$ ions ultimately drives ions across the pore, as proposed previously for native L-type channels (Almers and McCleskey, 1984; Hess and Tsien, 1984). Because all Ca channels cloned to date, including $\alpha_{1 \mathrm{E}}$, possess the four glutamate residues in similar positions, the data presented in this study suggest that additional structural determinants within the channel pore are likely to play a role in ion permeation. The existence of additional determinants for permeation is also supported by the recent report that an aspartate residue in the pore of the cardiac $\alpha_{1 \mathrm{C}}$ isoform is critical for $\mathrm{Ca}$ binding and Cd block (Parent et al., 1995). One conspicuous difference between $\alpha_{1 \mathrm{E}}$ and the remaining Ca channel subtypes occurs in domain I, where $\alpha_{1 \mathrm{E}}$ lacks a conserved aspartate residue at position 264. The absence of a negatively charged residue may affect the shape of the barrier 
profile within the pore. Future studies involving site-directed mutagenesis of each of the $\mathrm{Ca}$ channel subtypes may identify additional amino acid residues involved in permeation. In this regard, the unique properties of the $\alpha_{1 \mathrm{E}}$ channel may prove particularly useful.

In conclusion, our data are consistent with the previous proposal (Soong et al., 1993) that $\alpha_{1 \mathrm{E}}$ channels reflect a subset of native neuronal mid- to low-threshold $\mathrm{Ca}$ channels, and it is likely that additional gene products encode other types of T-type $\mathrm{Ca}$ channels. Ultimately, antisense and/or gene knockout experiments are required to establish conclusively the exact nature of the native counterpart of $\alpha_{1 \mathrm{E}}$ channels.

\section{REFERENCES}

Akaike N, Kostyuk PG, Osipchuk YV (1989) Dihydropyridine-sensitive low-threshold calcium channels in isolated rat hypothalamic neurones. J Physiol (Lond) 412:181-195.

Almers W, McCleskey EW (1984) Non-selective conductance in calcium channels of frog muscle: calcium selectivity in a single-file pore. J Physiol (Lond) 353:585-608.

Beam KG, Knudson CM (1988) Calcium current in embryonic and neonatal mammalian skeletal muscle. J Gen Physiol 91:781-798.

Bean BP (1985) Two kinds of calcium channels in canine atrial cells. J Gen Physiol 86:1-30.

Bourinet E, Charnet P, Stea A, Tomlinson JW, Snutch TP, Nargeot J (1994) Voltage dependent facilitation of a neuronal $\alpha_{1 \mathrm{C}}$ L-type calcium channel. EMBO J 13:5032-5039.

Byerly L, Chase PB, Stimers J (1985) Permeation and interaction of divalent cations in calcium channels of snail neurons. J Gen Physiol 85:491-518.

Carbone E, Lux HD (1987) Kinetics and selectivity of a low-voltageactivated calcium current in chick and rat sensory neurones. J Physiol (Lond) 386:547-570.

Charnet P, Bourinet E, Dubel SJ, Snutch TP, Nargeot J (1994) Calcium currents recorded from a neuronal $\alpha_{1 \mathrm{C}}$ L-type calcium channel in Xenopus oocytes. FEBS Lett 344:87-90.

de Leon M, Wang Y, Jones L, Perez-Reyes E, Wei X, Soong TW, Snutch TP, Yue DT (1995) Essential $\mathrm{Ca}^{2+}$-binding motif for $\mathrm{Ca}^{2+}$-sensitive inactivation of L-type $\mathrm{Ca}^{2+}$ channels. Science 270:1502-1506.

Dhallan RS, Yau KW, Schrader KA, Reed RR (1990) Primary structure and functional expression of a cyclic nucleotide-activated channel from olfactory neurons. Nature 347:184-187.

Dubel SJ, Starr TV, Hell J, Ahlijannian MK, Enyeart JJ, Catterall WA, Snutch TP (1992) Molecular cloning of the $\alpha 1$ subunit of an $\omega$-conotoxin-sensitive calcium channel. Proc Natl Acad Sci USA 89:5058-5062.

Dunlap K, Luebke JI, Turner TJ (1995) Exocytotic $\mathrm{Ca}^{2+}$ channels in the mammalian central nervous system. Trends Neurosci 18:89-98.

Dzhura I, Kostyuk P, Lyubanova O, Naidenov V, Shuba Y (1994) Expression of low-voltage activated $\mathrm{Ca}^{2+}$-channels from rat brain neurons in Xenopus oocytes. NeuroReport 5:1960-1962.

Ellinor PT, Zhang JF, Randall AD, Zhou M, Schwarz TL, Tsien RW, Horne WA (1993) Functional expression of a novel neuronal voltagedependent calcium channel. Nature 363:455-458.

Ellinor PT, Yang J, Sather WA, Zhang JF, Tsien RW (1995) $\mathrm{Ca}^{2+}$ channel selectivity at a single locus for high affinity $\mathrm{Ca}^{2+}$ interactions. Neuron 15:1121-1132.

Fox AP, Nowycky MC, Tsien RW (1987) Kinetic and pharmacological properties distinguishing three types of calcium currents in chick sensory neurones. J Physiol (Lond) 394:149-172.

Fujita Y, Mynlieff M, Dirksen RT, Kim MS, Niidome T, Nakai J, Friedrich T, Iwabe N, Miyata T, Furuchi T, Furutama D, Mikoshiba K, Mori Y, Beam KG (1993) Primary structure and functional expression of the $\omega$-conotoxin-sensitive $\mathrm{N}$-type calcium channel from rabbit brain. Neuron 10:585-598.

Galli A, Ferroni A, Bertollini L, Mazzanti M (1994) Inactivation of single $\mathrm{Ca}^{2+}$ channels in rat sensory neurons by extracellular $\mathrm{Ca}^{2+}$. J Physiol (Lond) 477:15-26.

Hagiwara S, Ohmori H (1982) Studies of calcium channels in rat clonal pituitary cells with patch electrode voltage clamp. J Physiol (Lond) 49:807-818.
Hell JW, Westenbroek RE, Warner C, Ahlijanian MA, Prystay W, Gilbert MM, Snutch TP, Catterall WA (1993) Identification and differential subcellular localization of the neuronal class C and class D L-type calcium channel $\alpha_{1}$ subunits. J Cell Biol 123:949-962.

Hess P, Tsien RW (1984) Mechanism of ion permeation through calcium channels. Nature 309:453-456.

Hess P, Lansman JB, Tsien RW (1986) Calcium channel selectivity for divalent and monovalent cations. J Gen Physiol 88:293-319.

Hille B (1992) Ionic channels of excitable membrane. Sunderland, MA: Sinauer.

Hiriat M, Matteson DR (1988) Na channels and two types of Ca channels in rat pancreatic $\mathrm{B}$ cells identified with the reverse hemolytic plaque assay. J Gen Physiol 91:617-639.

Huguenard JR, Prince DA (1992) A novel T-type current underlies prolonged $\mathrm{Ca}^{2+}$-dependent burst firing in GABAergic neurons of rat thalamic reticular nucleus. J Neurosci 12:3804-3817.

Imredy JP, Yue DT (1994) Mechanism of $\mathrm{Ca}^{2+}$-sensitive inactivation of L-type Ca2+ channels. Neuron 12:1301-1318.

Kasai H, Neher E (1992) Dihydropyridine-sensitive and $\omega$-conotoxinsensitive calcium channels in a mammalian neuroblastoma-glioma cell line. J Physiol (Lond) 448:161-188.

McDonald TF, Pelzer S, Trautwein W, Pelzer DJ (1994) Regulation and modulation of calcium channels in cardiac, skeletal, and smooth muscle cells. Physiol Rev 74:365-507.

Mori Y, Friedrich T, Kim MS, Mikami A, Naaki J, Ruth P, Bosse E, Hofmann F, Flockerzi V, Furuichi T, Mikoshiba K, Imoto K, Tanabe T, Numa S (1991) Primary structure and functional expression from complementary DNA of a brain calcium channel. Nature 350: 398-402.

Neely A, Olcese R, Wei X, Birnbaumer L, Stefani E (1994) $\mathrm{Ca}^{2+}$. dependent inactivation of a cloned cardiac $\mathrm{Ca}^{2+}$ channel $\alpha_{1}$ subunit $\left(\alpha_{1 \mathrm{C}}\right)$ expressed in Xenopus oocytes. Biophys J 66:1895-1903.

Neveu D, Quignard JF, Fernandez A, Richard S, Nargeot J (1994) Differential $\beta$-adrenergic regulation and phenotypic modulation of voltageactivated calcium currents in rat aortic myocytes. J Physiol (Lond) 479:171-182.

Nilius B, Hess P, Lansman JB, Tsien RW (1986) A novel type of cardiac calcium channel in ventricular cells. Nature 316:443-446.

Parent L, Davila DD, Gopalakrishnan M, Brown AM (1995) Aspartate residue D737 in pore II of the cardiac calcium channel $\alpha_{1 \mathrm{C}}$ subunit contributes to high-affinity calcium and cadmium binding. Biophys $\mathbf{J}$ 68:A264.

Perez-Reyes E, Yuan W, Wei X, Bers DM (1994) Regulation of the cloned L-type cardiac calcium channel by cyclic-AMP-dependent protein kinase. FEBS Lett 342:119-123.

Regan LJ (1991) Voltage-dependent calcium currents in Purkinje cells from rat cerebellar vermis. J Neurosci 11:2259-2269.

Sather WA, Tanabe T, Zhang JF, Mori Y, Adams ME, Tsien RW (1993) Distinctive biophysical and pharmacological properties of Class A (BI) calcium channel $\alpha_{1}$ subunits. Neuron 11:291-303.

Shuba YM, Teslenko VI, Savchenko AN, Pogorelaya NH (1991) The effect of permeant ions on single calcium channel activation in mouse neuroblastoma cells: ion-channel interaction. J Physiol (Lond) 443:25-44.

Soong TW, Stea A, Hodson CD, Dubel SJ, Vincent SR, Snutch TP (1993) Structure and functional expression of a member of the low voltageactivated calcium channel family. Science 260:1133-1136.

Stea A, Dubel SJ, Pragnell M, Leonard JP, Campbell KP, Snutch TP (1993) A $\beta$-subunit normalizes the electrophysiological properties of a cloned N-type $\mathrm{Ca}^{2+}$ channel $\alpha_{1}$-subunit. Neuropharmacology 32:1103-1116.

Stea A, Tomlinson JW, Soong TW, Bourinet E, Dubel SJ, Vincent SR, Snutch TP (1994) The localization and functional properties of a rat brain $\alpha_{1 \mathrm{~A}}$ calcium channel reflect similarities to neuronal Q- and P-type channels. Proc Natl Acad Sci USA 91:10576-10580.

Stea A, Soong TW, Snutch TP (1995a) Determinants of PKC-dependent modulation of a family of neuronal calcium channels. Neuron 15:929-940.

Stea A, Soong TW, Snutch TP (1995b) Voltage-gated calcium channels. Ligand- and voltage-gated ion channels. In: Handbook of receptors and channels (North RA, ed), pp 113-152. Boca Raton, FL: CRC.

Takahashi K, Ueno S, Akaike N (1991) Kinetic properties of T-type $\mathrm{Ca}^{2+}$ currents in isolated rat hippocampal CA1 pyramidal neurons. J Neurophysiol 65:148-155. 
Tang S, Mikala G, Bahinski A, Yatani A, Varadi G, Schwartz A (1993) Molecular localization of ion selectivity sites within the pore of a human L-type cardiac calcium channel. J Biol Chem 268:13026-13029.

Tomlinson JW, Stea A, Bourinet E, Charnet P, Nargeot J, Snutch TP (1993) Functional properties of a neuronal class C L-type calcium channel. Neuropharmacology 32: 1117-1126.

Tsien RW, Lipscombe D, Madison DV, Bley KR, Fox AP (1988) Multiple types of neuronal calcium channels and their selective modulation. Trends Neurosci 11:431-438.

Williams ME, Feldman DH, McCue AF, Brenner R, Velicelebi G, Ellis SB, Harpold MM (1992a) Structure and functional expression of $\alpha_{1}$, $\alpha_{2}$, and $\beta$ subunits of a novel human neuronal calcium channel subtype. Neuron 8:71-84.

Williams ME, Brust PF, Feldman DH, Patthi S, Simerson S, Maroufi A, McCue AF, Velicelebi G, Ellis SB, Harpold MM (1992b) Structure and functional expression of an $\omega$-conotoxin-sensitive human $\mathrm{N}$-type calcium channel. Science 257:389-395.
Williams ME, Marubio LM, Deal CR, Hans M, Brust PF, Philipson LH, Miller RJ, Johnson EC, Harpold MM, Ellis SB (1994) Structure and functional characterization of neuronal $\alpha_{1 \mathrm{E}} \mathrm{Ca}^{2+}$ channel subtype. J Biol Chem 269:22347-22357.

Yang J, Ellinor PT, Sather WA, Zhang JF, Tsien RW (1993) Molecular determinants of $\mathrm{Ca}^{2+}$ selectivity and ion permeation in L-type $\mathrm{Ca}^{2+}$ channels. Nature 366:158-161.

Yue DT, Marban E (1990) Permeation in the dihydropyridine-sensitive calcium channel: multi-ion occupancy but no anomalous mole fraction effect between $\mathrm{Ba}^{2+}$ and $\mathrm{Ca}^{2+}$. J Gen Physiol 95:911-939.

Zamponi GW, Bourinet E, Snutch TP (1996) Nickel block of a family of neuronal calcium channels. Subtype- and subunit-dependent action at multiple sites. J Membr Biol 151:77-90.

Zhang JF, Randall AD, Ellinor PT, Horne WA, Sather WA, Tanabe T, Schwarz TL, Tsien RW (1993) Distinctive pharmacology and kinetics of cloned neuronal $\mathrm{Ca}^{2+}$ channels and their possible counterparts in mammalian CNS neurons. Neuropharmacology 32:1075-1080. 